\title{
Erratum
}

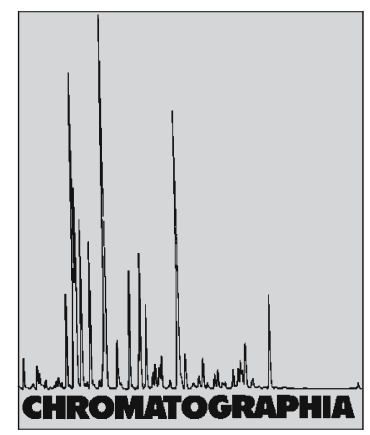

2008, 67, 501

\section{Diterpenoic Acids Analysis Using a Coupled TLC-Surface-Enhanced Raman Spectroscopy System}

\author{
Andrej Oriňák ${ }^{1, 凶}$, Ivan Talian ${ }^{2}$, Evtim V. Efremov ${ }^{3}$, Freek Ariese $^{3}$, Renata Oriňáková $^{1}$ \\ ${ }^{1}$ Institute of Chemistry Sciences, Department of Physical Chemistry, University of P. J. Šafárik, Moyzesova 11, 04154 Košice, \\ Slovak Republic; E-Mail: andrej.orinak@upjs.sk \\ ${ }^{2}$ Department of Analytical Chemistry, Faculty of Science, Comenius University, Mlynská Dolina, 84215 Bratislava 4, Slovak Republic \\ 3 Department of Analytical Chemistry and Applied Spectroscopy, Vrije Universiteit Amsterdam, De Boelelaan 1083, 1081 HV Amsterdam, \\ The Netherlands
}

\section{Erratum to: Chromatographia (2008) 67:315-319 DOI 10.1365/s10337-007-0474-5}

Unfortunately, the last author's name (R.O.) was spelled incorrectly. The correct name is Renata Oriňáková. 